Vol. 6, No. 1 Januari - Juni 2017

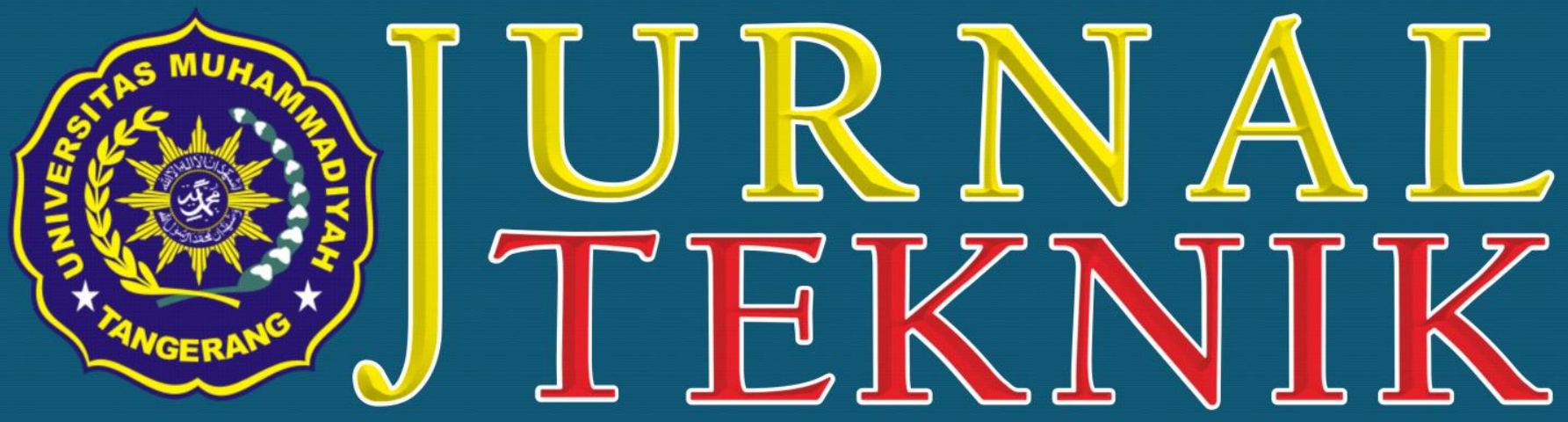

Alamat Redaksi: Jl. Perintis Kemerdekaan I No. 33, Cikokol Tangerang - TIp. (021) 51374916

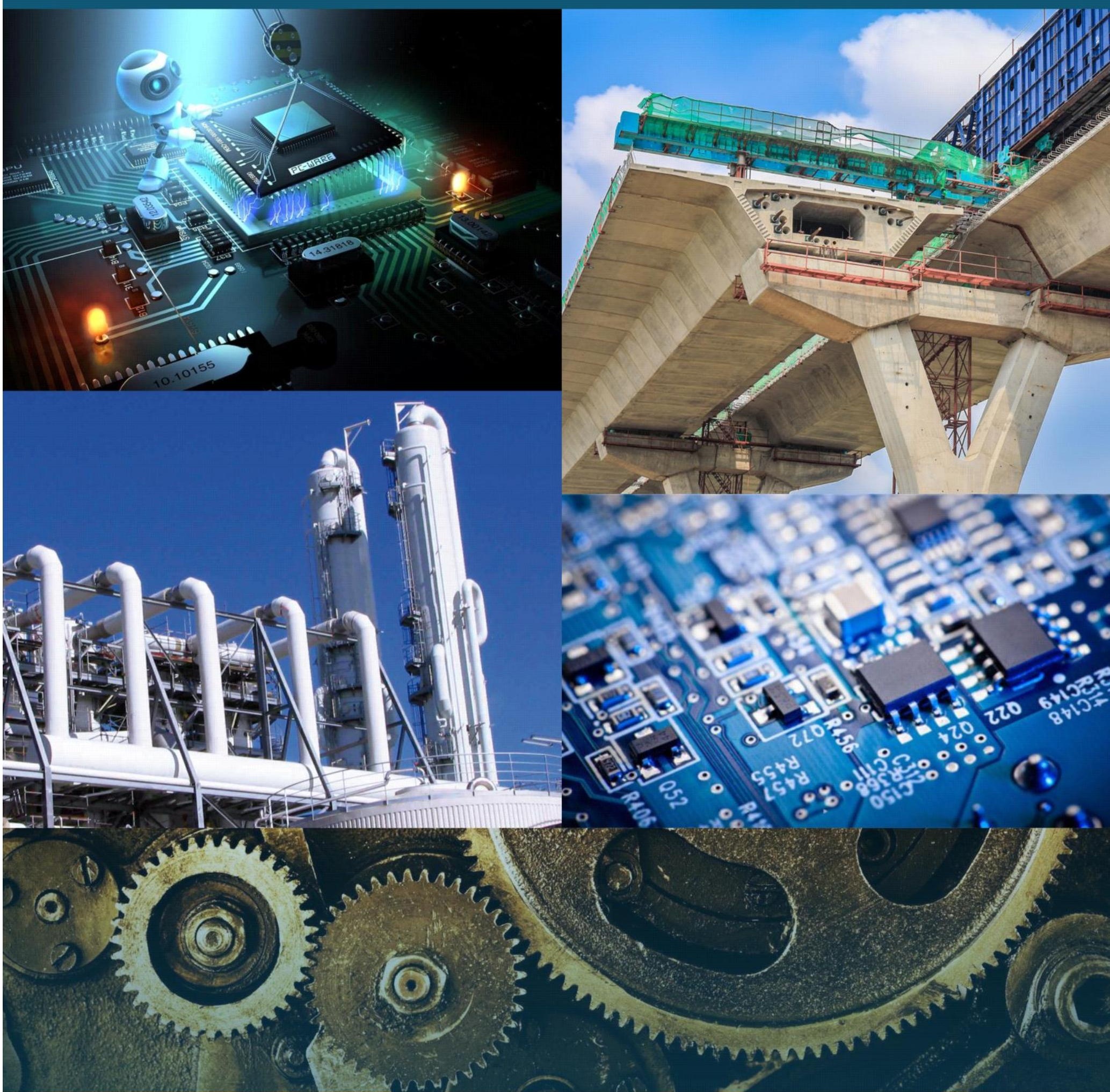




\section{J U R N A L TEKN I K}

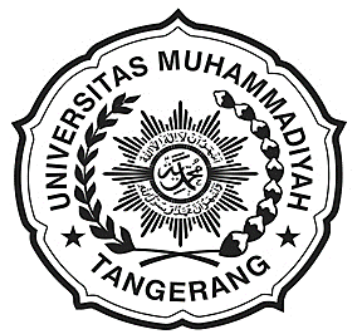

\section{UNIVERSITAS MUHAMMADIYAH TANGERANG}

Pelindung:

Dr. H. Achmad Badawi, S.Pd., SE., MM. (Rektor Universitas Muhammadiyah Tangerang)

Penanggung Jawab:

Ir. Saiful Haq, ST., M.Si.

(Dekan Fakultas Teknik)

Pembina Redaksi:

Rohmat Taufik, ST., M.Kom.

Drs. H. Syamsul Bahri, MSi.

Pimpinan Redaksi:

Ir. Sumardi Sadi, S.Pd., ST., MT.

Redaktur Pelaksana:

Yafid Efendi, ST, MT.

Editor Jurnal Teknik UMT:

Ir. Sumardi Sadi, S.Pd., ST., MT.

Dewan Redaksi:

Ir. Ali Rosyidin, ST., MM., MT.

Tri Widodo, ST.,MT.

Tina Herawati, ST., MT

Almufid, ST., MT.

Siti Abadiah, ST., MT.

M. Jonni, SKom., MKom.

Syepry Maulana Husain, S.Kom., M.Kom.

Ir. H. Bayu Purnomo, ST., MT

Kasubag:

Ferry Hermawan, MM.

Keuangan:

Elya Kumalasari, S.Ikom.

Setting \& Lay Out:

Muhlis, S.E

Saiful Alam, SE.

Mitra Bestari:

Prof. Dr. Aris Gumilar

Ir. Doddy Hermiyono, DEA

Dr. Ir. Budiyanto, MT.

Dr. Alimuddin, ST., MM., MT

J U R N A L T E K N I K

Diterbitkan Oleh:

Fakultas Teknik Universitas Muhammadiyah Tangerang

Alamat Redaksi:

Jl. Perintis Kemerdekaan I No. 33, Cikokol Tangerang Tlp. (021) 51374916

\begin{tabular}{|c|c|c|c|c|c|}
\hline \multirow{2}{*}{$\begin{array}{c}\text { Jurnal } \\
\text { Teknik }\end{array}$} & 6 & 1 & $1-97$ & $\begin{array}{c}\text { Jan'-Juni } \\
2017\end{array}$ & ISSN \\
\cline { 2 - 6 } & $2302-8734$ \\
\hline
\end{tabular}

\section{DAFTAR ISI}

1. PROSES PEMBUATAN ALAT PEMBUKA KALENG CAT DENGAN METODE CETAK PASIR (SAND CASTING) - 1-11 Ali Rosyidin

2. ANALISA DAN PERANCANGAN SISTEM KENDALI PLC XBC MINI BAS - 12-18 Alim Hardiansyah \& Bambang Suardi Waluyo

3. PENGATUR KESTABILAN SUHU PADA EGG INCUBATOR BERBASIS ARDUINO - 19-22

Abel Putra Hidayah \& Sumardi Sadi

4. METODE PEMBUATAN PONDASI BORE PILE DENGAN KINGPOST DAN METODE PONDASI DINDING PENAHAN TANAH DIAFRAGMA WALL - 23-29

Almufid

5. RANCANG BANGUN SIMULASI PENGENDALI LAMPU LALU LINTAS PADA PERSIMPANGAN DENGAN LIMA JALUR - 30-39

Rahma Farah Ningrum, Puji Catur Siswipraptini, \& Rosida N. Aziza

6. PERANCANGAN PROGRAM APLIKASI PENGENALAN WAJAH DENGAN MENERAPKAN METODE PRINCIPAL COMPONENT ANALYSIS DAN JARINGAN SYARAF TIRUAN - 40-49

M. Lutfi Aksani

7. KAJIAN PENERAPAN SI / TI DALAM MENINGKATKAN KUALITAS PEMBELAJARAN PADA TRAINING CENTER DENGAN MENGGUNAKAN METODOLOGI DeLone And McLean: STUDI KASUS PADA BINUS CENTER JAKARTA - 50-62 Nyoman Ayu Gita Gayatri \& GG Faniru Pakuning Desak

8. RANCANG BANGUN APLIKASI PEMBELAJARAN MATEMATIKA SD KELAS 6 BERBASIS ANDROID PADA SDN CIMONE 1 TANGERANG - 63-69

Winda Anggraeni \& Sri Mulyati

9. RANCANG BANGUN MESIN PERAJANG SINGKONG INDUSTRI RUMAHAN BERDAYA RENDAH - 70-76

Yafid Effendi \& Agus Danang Setiawan

10. RANCANG BANGUN TONGKAT ULTRASONIK UNTUK PENYANDANG TUNA NETRA BERBASIS ARDUINO UNO - 77-82

Bayu Purnomo \& Basuki Isnanto

11. ENTERPRISE RISK MANAGEMENT PADA CLOUD COMPUTING - 83-87

Samudera Dipa Legawa

12. ANALISIS NETWORK PLANNING DENGAN CRITICAL PATH METHOD (CPM) PADA PROYEK UNINTERATUBLE POWER SUPPLY (UPS) 80KVA PADA PT. HARMONI MITRA SUKSES (STUDI KASUS: RSAB HARAPAN KITA, JAKARTA) - 88-97

Hermanto, Novy Fauziah, \& Elfitria Wiratmani 


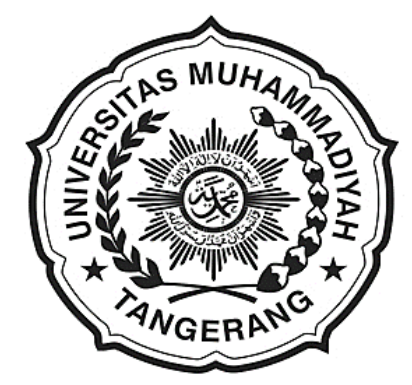

\section{Sambutan Dekan \\ Fakultas Teknik \\ Universitas Muhammadiyah Tangerang}

Puji Syukur kehadirat Allah Swt. karena berkat karunia dan ijin-Nyalah Tim penyusun Jurnal Teknik Fakultas Teknik Universitas Muhammadiyah Tangerang dapat menyelesaikan tugasnya tepat sesuai dengan waktu ditetapkan.

Saya menyambut baik diterbitkannya Jurnal Teknik Vol. 6 No. 1, Januari-Juni 2017, terbitnya jurnal ini, merupakan respon atas terbitnya Peraturan Menteri Pendidikan Nasional No. 17 Tahun 2010 tentang Pencegahan dan Penanggulangan Plagiat di Perguruan Tinggi; Surat Dirjen Dikti Nomor 2050/E/T/2011 tentang kebijakan unggah karya ilmiah dan jurnal; Surat Edaran Dirjen Dikti Nomor 152/E/T/2012 tertanggal 27 Januari 2012 perihal publikasi karya ilmiah yang antara lain menyebutkan untuk lulusan program sarjana terhitung mulai kelulusan setelah 2012 harus menghasilkan makalah yang terbit pada jurnal ilmiah.

Terbitnya Jurnal ini juga diharapkan dapat mendukung komitmen dalam menunjang peningkatan kemampuan para dosen dan mahasiswa dalam menyusun karya ilmiah yang dilandasi oleh kejujuran dan etika akademik. Perhatian sangat tinggi yang telah diberikan rektor Universitas Muhammadiyah Tangerang khususnya mengenai plagiarism dan cara menghindarinya, diharapkan mampu memacu semangat dan motivasi para pengelola jurnal, para dosen dan mahasiswa dalam menyusun karya ilmiah yang semakin berkualitas.

Saya mengucapkan banyak terimakasih kepada para penulis, para pembahas yang memungkinkan jurnal ini dapat diterbitkan, dengan harapan dapat dimanfaatkan seoptimal mungkin dalam peningkatan kualitas karya ilmiah.

Dekan Fakultas Teknik

Universitas Muhammadiyah Tangerang,

\section{Ir. Saiful Haq, M.Si.}




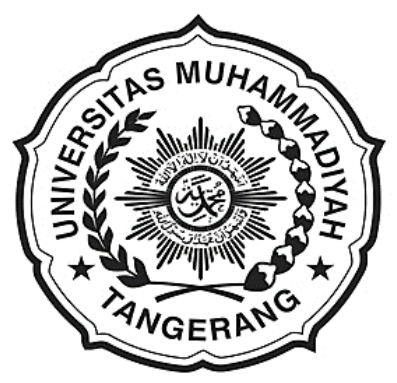

\section{Pengantar Redaksi}

Jurnal Teknik

Universitas Muhammadiyah Tangerang

Puji dan Syukur Alhamdulillah kami panjatkan kehadapan Allah Swt. atas karunia dan lindungan-Nya sehingga Jurnal Teknik Vol. 6 No. 1 edisi Januari-Juni 2017 dapat diterbitkan.

Menghasilkan karya ilmiah merupakan sebuah tuntutan perguruan tinggi di seluruh dunia. Tri Dharma Perguruan Tinggi yaitu darma pendidikan, darma penelitian, dan darma pengabdian kepada masyarakat mendorong lahirnya dinamika intelektual diantaranya menghasilkan karyakarya ilmiah. Penerbitan Jurnal Teknik ini dimaksudkan sebagai media dokumentasi dan informasi ilmiah yang sekiranya dapat membantu para dosen, staf dan mahasiswa dalam menginformasikan atau mempublikasikan hasil penelitian, opini, tulisan dan kajian ilmiah lainnya kepada berbagai komunitas ilmiah.

Buku Jurnal yang sedang Anda pegang ini menerbitkan 12 artikel yang mencakup bidang teknik sebagaimana yang tertulis dalam daftar isi dan terdokumentasi nama dan judul-judul artikel dengan jumlah halaman 1-97 halaman.

Jurnal Teknik ini tentu masih banyak kekurangan dan masih jauh dari harapan, namun demikian tim redaksi berusaha untuk ke depannya menjadi lebih baik dengan dukungan kontribusi dari semua pihak. Harapan Jurnal Teknik akan berkembang menjadi media komunikasi intelektual yang berkualitas, aktual dan faktual sesuai dengan dinamika di lingkungan Universitas Muhammadiyah Tangerang.

Tak lupa pada kesempatan ini kami mengundang pembaca untuk mengirimkan naskah ringkasan penelitiannya ke redaksi kami. Kami sangat berterimakasih kepada semua pihak yang telah membantu penerbitan Jurnal Teknik ini semoga buku yang sedang Anda baca ini dapat bermanfaat.

Pimpinan Redaksi Jurnal Teknik

Universitas Muhammadiyah Tangerang,

Ir. Sumardi Sadi, S.Pd., ST., MT. 


\title{
ANALISA DAN PERANCANGAN SISTEM KENDALI PLC XBC MINI BAS
}

\author{
Alim Hardiansyah ${ }^{1)}$, Bambang Suardi Waluyo ${ }^{2)}$ \\ Dosen Teknik Infomatika, Teknik Mesin \\ Institut Sains dan Teknologi Al-Kamal (ISTA) \\ E-mail: hardiansyahalim@if.ista.ac.id, bambang_waluyo07@yahoo.com
}

\begin{abstract}
ABSTRAK
Perkembangan teknologi otomasi saat ini sudah sangat maju, seperti sistem otomasi menggunakan PLC (Programable Logic Controller), PLC dengan HMI (Human Machine Interface) hingga sistem SCADA (Supervisory Control and Acquisition). Agar dapat mengikuti perkembangan dari sistem otomasi perlu dilakukan penelitian untuk mengetahui cara kerja dari masing-masing sistem otomasi. Selain itu penelitian ini juga bertujuan untuk mengetahui bagaimana merancang dan menerapkan ketiga sistem otomasi tersebut.Penelitian ini juga dilakukan dengan menguji sistem otomasi PLC, sistem otomasi PLC dengan HMI dan sistem SCADA dalam mengendalikan sistem kerja lampu. Sistem otomasi terdiri dari PLC dengan HMI yang berfungsi untuk mengendalikan dalam mengoperasikan kerja lampu. Selanjutnya sistem SCADA terdiri dari sebuah PLC sebagai RTU (Remote Terminal Unit), sebuah PLC sebagai MTU (Master Terminal Unit), dan komputer dengan perangkat lunak G5000 untuk mengendalikan mengawasi dan mengakuisisi data lampu. Hasil penelitian ini menunjukan bahwa ketiga sistem otomasi bekerja dengan baik. Hal ini terlihat dari tampilnya data dan informasi mengenai nyalanya lampu pada alat peraga pada HMI maupun laptop sesuai dengan keadaan sebenarnya. Selain itu pengoperasian lampu juga berhasil dengan bisa nyala pada alat peraga.
\end{abstract}

Kata Kunci: PLC XBC, HMI, SCADA, Sistem Kendali Mini Bas.

\begin{abstract}
Development of automation technology is now very advanced, such as the automation using system PLC (Programmable Logic Controller). PLC with HMI (Human Machine Interface) to a SCADA system ( Supervisory Control and Acquisition ). order to follow the development of automation systems need to investigate the workings of each of the automation system. In addition, this study also aims to determine how to design and implement automation system such third.This study was also conducted with test automation systems PLC, PLC automation systems with HMI and SCADA systems to control lighting systems work. The automation system consists of a PLC with the HMI that serves to control the lights in operating working. Then the system SCADA system consists of a PLC as an RTU (Remote Terminal Unit), a PLC as MTU (Master Terminal Unit), and $G 5000$ computer with software to control and over see the data acquiring light.These results indicate that the three automation system works well. This is evident from the appearance of the data and information on the flame lights on props on HMI or laptop according to the actual situation. Besides successful operation of the lamp also can live on props.
\end{abstract}

Keywords: PLC XBC, HMI, SCADA, Control Systems Mini Bas. 


\section{PENDAHULUAN}

Otomasisasi merupakan salah satu realisasi dari perkembangan teknologi, dan merupakan satu-satunya alternatif yang tidak dapat dielakkan lagi untuk memperoleh sistem kerja yang sederhana, praktis dan efisien, sehingga bisa memperoleh hasil dengan tingkat keakuratan yang tinggi. Dalam segi waktu yang diperlukan juga harus dipertimbangkan, karena semakin pendek waktu yang diperlukan untuk melakukan aktifitas maupun produksi, maka akan mendapatkan kualitas lebih, Berdasarkan pertimbangan-pertimbangan diatas, untuk menunjang proses otomasisasi agar faktor-faktor kecepatan, akurasi dan efisiensi dapat tercapai dibutuhkan sistem kontrol. Programmable Logic Control (PLC) merupakan salah satu kontroler yang umum digunakan. Dilihat dari sisi perkembangan teknologi, sistem kontrol dapat dikelompokkan menjadi dua jenis yaitu sistem kontrol konvensional dan sistem kontrol terprogram.

Berdasarkan permasalahan terhadap kontrol konvensional dan upaya untuk menggantikannya dengan kontrol berbasis PLC yaitu:

1. Bagaimana membuat program sebuah alat kontrol untuk PLC LS Type XBC menggunakan sofware Ladder Diagram;

2. Bagaimana memasukkan program yang sudah dibuat ke dalam memory PLC LS Type XBC; dan

3. Bagaimana membuat tampilan dari sisi Teknik Informatikanya yang lebih interaktif dengan software Scada.

\section{PROGRAMMABLE LOGIC CONTROLLER}

Mikrokontroler adalah sebuah sistem komputer yang dibangun pada sebuah keeping (Chip) tunggal. Jadi hanya dengan sebuah keeping IC saja dapat dibuat sistem computer yang dapat dipergunakan untuk mengontrol sebuah peralatan. (Malik, 2009).[1].

Sistem kontrol harus bisa melakukan pengontrolan serangkain kejadian atau mempertahankan agar sejumlah variable tetap bernilai konstan atau melakukan suatu perubahan yang telah ditetapkan sebelumnya. Untuk merancang sebuah sistem kontrol yang terpisah untuk tiap-tiap kebutuhan pengontrolan, kita dapat mempergunakan sistem kontrol dasar yang sama untuk segala situasi apabila kita memanfaatkan sebuah sistem berbasis mikroprosesor dan menuliskan sebuah program yang menginstruksikan mikroprosesor untuk memberikan reaksi pada setiap sinyal input dari dan menghasilkan output yang dibutuhkan. Dengan mengubah intruksiintruksi di dalam program, kita dapat menggunakan sistem mikroprosesor yang sama untuk berbagai aplikasi kontrol. (Setiawan, 2005).[2].

Mikrokontroler adalah sebuah sistem komputer yang dibangun pada sebuah keeping (Chip) tunggal. Jadi hanya dengan sebuah keeping IC saja dapat dibuat sistem computer yang dapat dipergunakan untuk mengontrol sebuah peralatan. (Malik, 2009).

Programmable logic controller merupakan suatu bentuk khusus pengontrol berbasis mikroprosesor yang memanfaatkan memori yang dapat diprogram untuk meyimpan instruk-si-instruksi dan mengimplementasikan fungsi-fungsi logika, sequencing, pewaktuan (timing), pencacahan (counting) dan aritmatika guna mengontrol mesin-mesin dan proses-proses. (Setiawan, 2005).

\section{PERANCANGAN}

\subsection{Analisa Cara Kerja Mini Bas}

Selanjutnya, sebelum membuat program yang akan dimasukkan ke PLC, langkah pertama adalah membuat analisa terhadap cara kerja peralatan yang akan dikontrol dengan PLC tersebut. Alat atau sistem yang akan dibuat di sini adalah sebuah alat kendali menggunakan PLC untuk mengontrol sebuah panel pembagi yang menyuplai ke setiap ruangan.

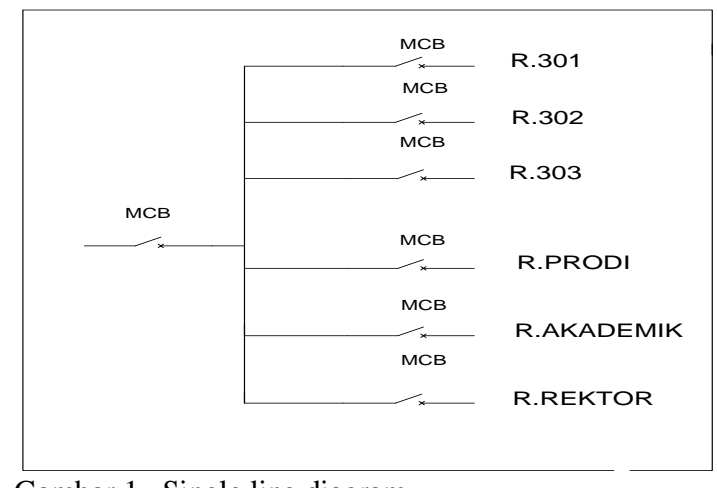

Gambar 1. Single line diagram. 


\subsection{Membuat program ladder diagram}

Untuk membuat sebuah program yang akan dimasukkan ke PLC, kita harus memahami dasar pembuatan program menggunakan diagram tangga/ladder diagram. Programmable Logic Controller (PLC) pada dasarnya adalah sebuah komputer yang khusus dirancang untuk mengontrol suatu proses atau mesin. Software yang umum digunakan untuk pemrograman PLC adalah Ladder diagram atau diagram tangga.
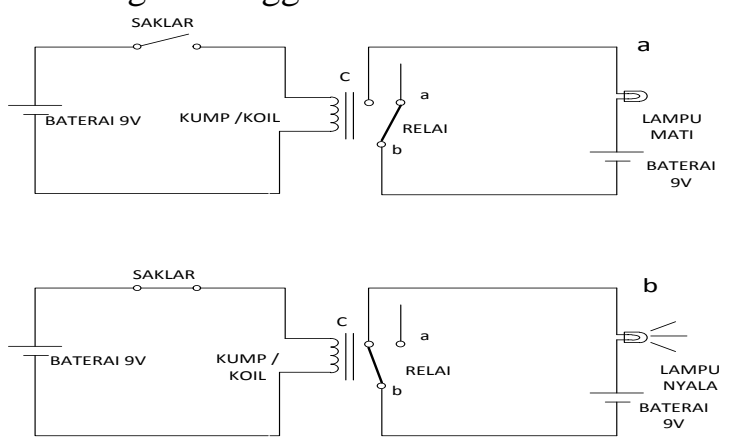

Gambar 2. Cara Kerja Relay.

Tampak pada gambar pertama di atas, sakelar dalam kondisi terbuka sehingga kumparan relay tidak teraliri arus. Saat relay dalam kondisi tidak aktif ini, b.akan terhubung dengan a, memutus aliran baterai ke lampu sehingga lampu tidak menyala. Pada gambar kedua, sakelar dalam kondisi tertutup hingga kumparan relay teraliri arus yang membuat relay dalam kondisi aktif. Ketika aktif, akibat gaya electromagnet dalam relay $b$ akan terhubung dengan c. Karena b dan c terhubung, arus akan mengalir kelampu sehingga lampu dapa tmenyala.

Lebih jauh gambar diatas dapat disederhanakan menjadi susunan simbol seperti berikut ini:

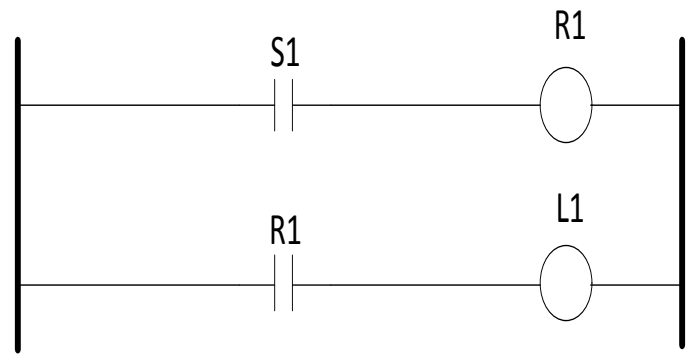

Gambar 3. Diagram tangga sederhana.

Disebut demikian karena bentuknya yang mirip dengan sebuah tangga. Dua buah garis vertikal di sisi kiri dan kanan melambangkan catu daya. Saat relay dalam kondisi tidak aktif, sakelar dalam kondisi terbuka sehingga di gambar dengan kontak NO.

\subsection{Membuat program PLC}

Berdasarkan analisa cara kerja lampu dan aturan mengenai diagram tangga/ladder diagram kita bisa membuat program PLC untuk mengontrol panel tersebut. Dari uraian cara kerja lampu di atas, sebenarnya bisa dibuat sebuah control konvensional menggunakan relay dan timer. Rangkain kontrol konvensional tersebut adalah seperti gambar berikut:

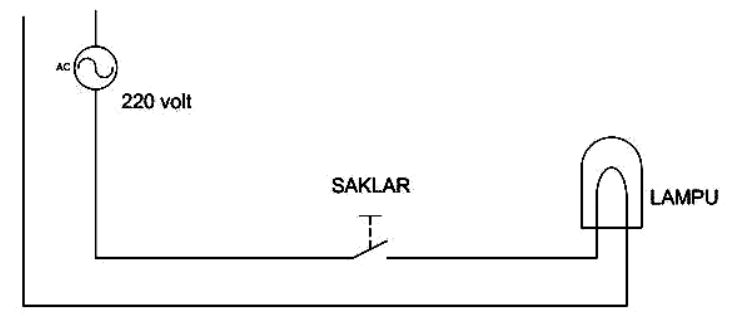

Gambar 4. Rangkaian kontrol konvensional.

Dari rangkaian konvensional ini dapat dengan mudah dibuat program PLC menggunakan ladder diagram. Hanya diperlukan instruksi-instruksi khusus untuk membuat program ini. Software yang digunakan adalah software pabrikan berupa CD yang sudah termasuk satu paket dengan modul PLC nya. Ini adalah jendela tempat membuat diagram tangga.

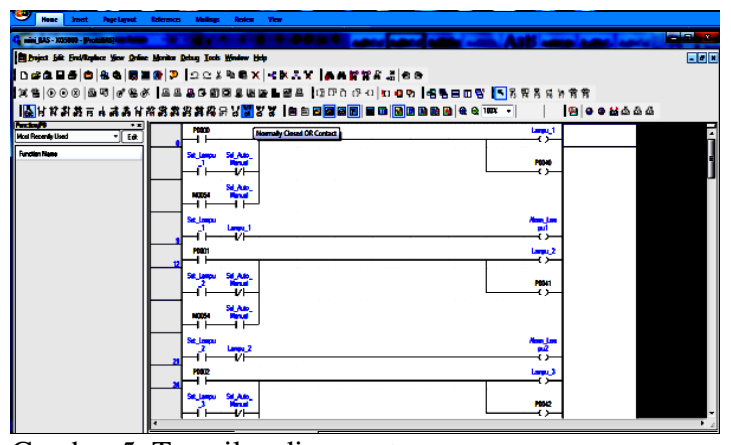

Gambar 5. Tampilan diagram tangga.

Setelah seluruh rangkaian diagram tangga selesai dibuat, sebelum kita masukkan ke dalam memory PLC, kita teliti dan dikoreksi lagi agar tidak terdapat kesalahan. Program yang sudah disediakan oleh pabrikan PLC ini sudah dilengkapi juga dengan program untuk simulasi. Sehingga kesalahan-kesalahan dalam pembuatan program diagram tangga 
dapat diketahui pada saat simulasi ini.

Dari menu utama disini ada pilihan menu lampu, menu denah lantai untuk lampu, dan menu logging dimana masing-masing menu tersebut bisa di operasikan sesuai dengan fasilitas yang ada kita bisa memilih salah satu menu yang akan kita buka atau kita akan operasikan

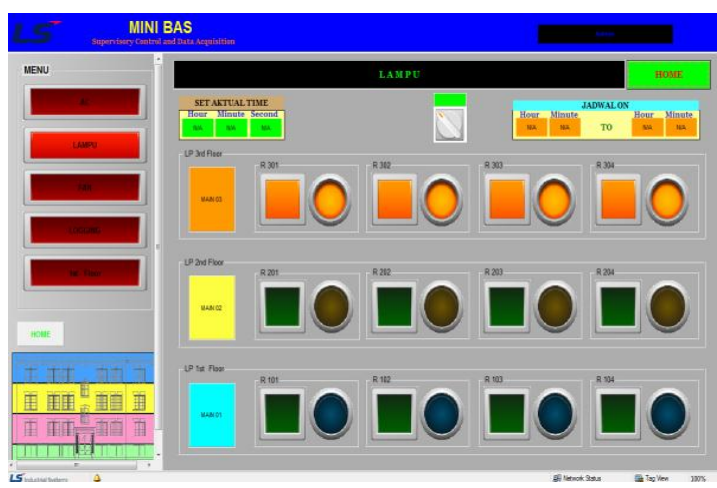

Gambar 6. Tampilan Sub Menu Lampu.

Pada sub menu lampu disini terdapat pilihan set actual time (SAT), Selector Switch, menu Schedule, menu tombol dan lampu. Untuk bisa membuka dan mengoperasikan pada halaman menu ini terlebih dahulu harus mengatur menu jam yang ada disesuaikan dengan jam yang aktual, karena nantinya diharapkan akan sesuai dengan waktu nyala lampu yang kita inginkan. Setelah mengatur menu jam atur posisi selektor switch ke posisi auto kemudian langkah selanjutnya mengisi jam schedule menyala lampu, sebagai contoh lampu nyala pada jam kantor antara pukul 07.30 sampai dengan pukul 17.30 wib. Setelah semua kegiatan input selesai secara otomatis lampu akan menyala.

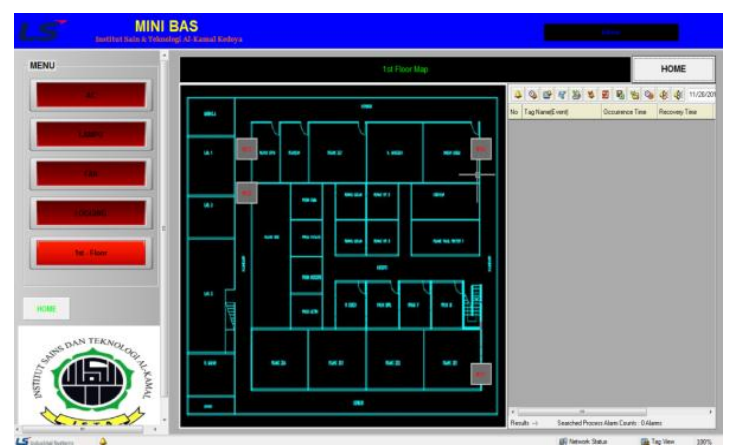

Gambar 7. Tampilan denah lampu.

Pada halaman denah lampu ini kita bisa mengoperasikan untuk menghidupkan dan mematikan lampu dari menu yang tersedia dihalaman ini. Untuk mengoperasikan lampu bisa pilih salah satu simbul panel yang ada sesuai dengan keinginan kita dimana ruangan yang akan kita operasikan lampunya.

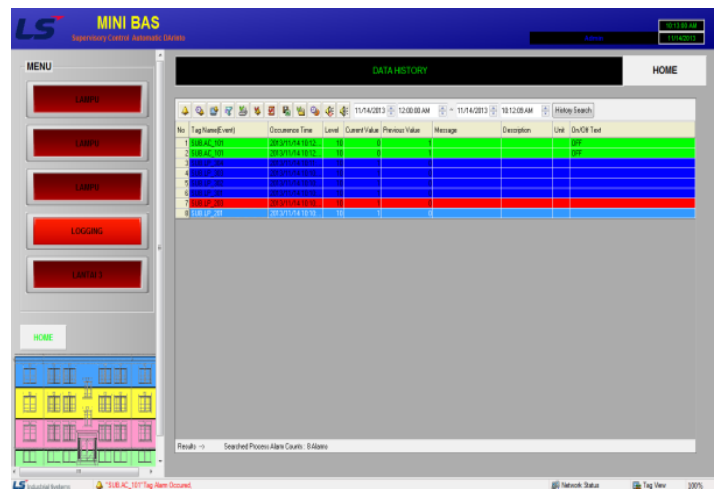

Gambar 8. Tampilan Logging Data History

Pada halaman menu logging ini berisi tentang data history dari semua aktifitas yang pernah dilakukan oleh operator atau teknisi. Dari halaman data history ini bisa dilihat detail lampu kapan nyala, detail lampu kapan mati, dan bila terjadi gangguan pada jaringan disitu akan muncul indikasi alarm, dari semua kegiatan aktifitas akan dicatat jam tanggal hari dan tahun kejadian eksekusi peralatan tersebut.

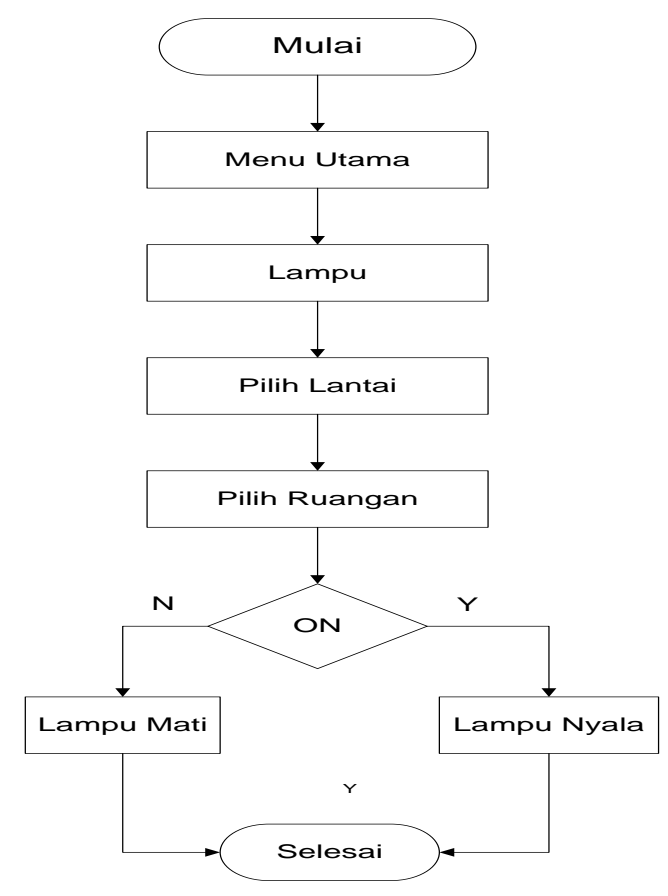

Gambar 9 Tampilan Flowchart lampu. 


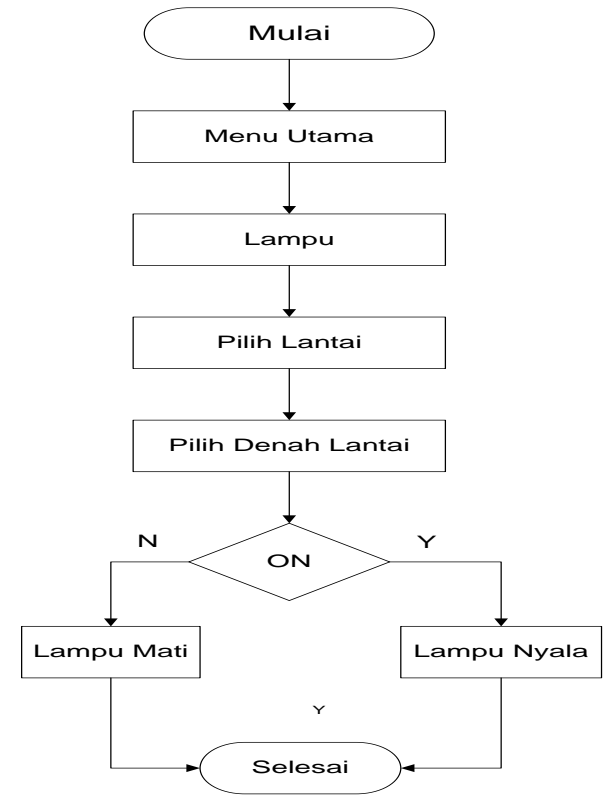

Gambar 10. Flowchart pengoperasian lampu

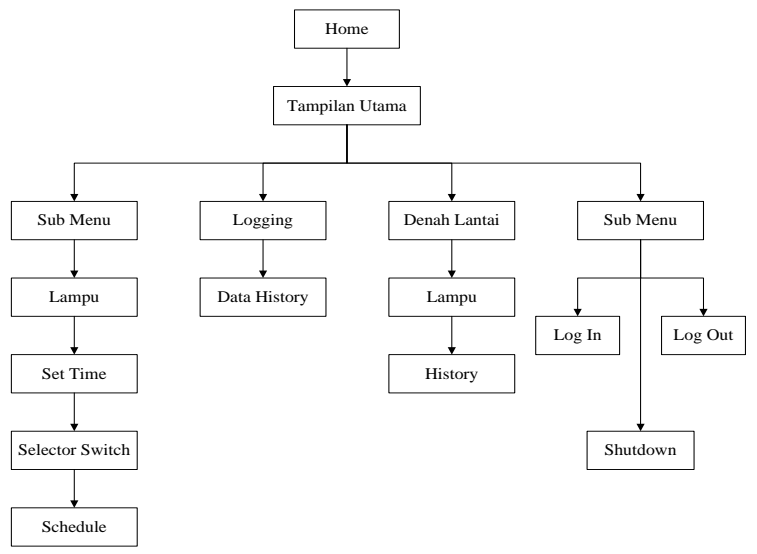

Gambar 11. Flowchart Bagan Sistem Mini Bas

\section{HASIL DAN PEMBAHASAN \\ 4.1 Pengoperaian PLC}

Pada bagian terdahulu telah dijelaskan mengenai langkah-langkah pembuatan kontrol menggunakan PLC yang diprogram dengan menggunakan Diagram Tangga. Dalam bagian ini akan diuraikan bagaimana pengoperasian PLC tersebut. Namun sebelum mengoperasikan PLC ini, kita perlu mengetahui kaki mana saja yang digunakan sebagai input dan output PLC ini. Berikut gambar kaki-kaki input dan output yang terdapat di dalam PLC type XBC yang terdiri dar $10 \mathrm{I} / \mathrm{O}$ (sepuluh input/output). Artinya PLC ini mempunyai 6 input dan 4 output.

\subsection{Langkah-langkah pengoperasian PLC}

Secara garis besar ada tiga langkah pengoperasian PLC, yaitu:

1. Menyiapkan seluruh penyambungan;

2. Melakukan simulasi pada sistem; dan

3. Mengaplikasikan PLC pada panel.

\subsection{Pengujian rangkaian PLC}

Untuk melakukan pengujian ini, metodenya adalah dengan menyambungkan/menghubungkan ketiga alat (catudaya, alat simulasi dan PLC) yang sudah siap digunakan. Sambungkan input dan output PLC kerangkaian simulasi, sambungkan catudaya kerangkaian simulasi, dan sambungkan power source 220 Volt. Untuk mengetahui proses berjalannya program PLC, kabel komunikasi serial antara PLC dan komputer dipasang diport yang telah tersedia. Setelah semua sudah siap, kemudian dilakukan pengujian dengan cara sebagai berikut.

Pertama-tama kita sambungkan PLC dengan komputer atau laptop. Pastikan komunikasi antara PLC dan computer sudah tersambung dan bekerja dengan baik.Tujuan kita menyambungkan antara PLC dengan komputer adalah agar kita dapat memonitor secara langsung urutan-urutan bekerjanya program ladder diagram, dan juga bisa melakukan editing atau mengubah program padasaat PLC sedang bekerja.Langkah-langkah agar PLC On Line dengan computer adalah sebagai berikut:

Metode on line antara PLC dan komputer dengan cara membuka file yang sudah di download ke PLC. Tujuan kita menyambungkan antara PLC dengan komputer adalah agar kita dapat memonitor secara langsung urutanurutan bekerjanya program ladder diagram, dan juga bisa melakukan editing atau mengubah program padasaat PLC sedang bekerja. Langkah-langkah agar PLC On Line dengan komputer adalah sebagai berikut:

Metode on line antara PLC dan komputer dengan cara membuka file yang sudah di download ke PLC.

1. Buka Software XG 5000;

2. Klik Project;

3. Kliknama file;

4. Klik On Line;

5. Klik connect;

6. Klik Monitor; 
7. Klik Start monitoring; dan

8. Simulasikan alat.

Untuk berhenti dari mode on line langkah-langkahnya sebagai berikut:

1. Klik monitoring;

2. Klik stop monitoring;

3. Klik On Line;

4. Klik Disconnect; dan

5. Close (timbul tab barupilih NO).

Metode on line antara PLC dan computer dengan cara meng up load file yang berada di dalam PLC. Cara ini digunakan apabila di dalam computer belum ada program yang dimaksud.

1. Buka software $X G 5000$;

2. Klik Project;

3. Klik Open from PLC;

4. Lakukan setting connection;

5. Klik connect atau $O K$;

6. Klik New program;

7. Klik Monitor; dan

8. Klik Start Monitoring.

Untuk berhent idari mode on line langkah-langkahnya sebagai berikut:

1. Klik monitoring;

2. Klik stop monitoring;

3. Klik On Line;

4. Klik Disconnect; dan

5. Close (timbul tab barupilih NO).

Mengedit program sambil RUN (PLC sedang bekerjadan on line dengan computer). Pengeditan program secara on line ini hanya bisa dilakukan setelah langkah open from PLC, dan dilakukan setelah kita meng-klik New program (langkah nomor 6 padametode on line antara PLC dengan computer dengan carameng up load dari PLC)

1. Klik On Line;

2. Klik Start Online Editing;

3. Lakukan pengeditan program (LD); dan

4. Save.

Untuk berhenti dari mode on line editing langkah-langkahnya sebagai berikut:

1. Klik On line;

2. Klik End Online Editing.

Setelah komunikasi antara PLC dan komputer bekerja dengan baik dansistem monitoring sudah bisa ditampilkan di layar komputer, langkah selanjutnya adalah mensimulasikan alat peraga dengan langkahlangkah sebagai berikut:

1. Matikan semua saklar yang digunakan untuk mewakili status power listrik dari PLN. Pada langkah ini semua circuit breaker harus dalam kondisi OFF; dan

2. Hidupkan saklar yang mewakili status power dari PLN, beberapa saat setelah saklar di hidupkan, circuit breaker incoming PLN harus berubah ke kondisi hidup.

\subsection{Membuat dokumentasi program}

Untuk memudahkan penanganan apabila terjadi masalah pada program PLC, data yang sudah dimasukkan ke PLC harus dibuatkan dokumentasi. Dokumentasi ini memuat diagram tangga dari keseluruhan program, memuat keterangan-keterangan dari tiap-tiap input dan out put, dan juga ditambah dengan keterangan dari alur dan cara kerja program. Dokumentasi ini sebaiknya dilakukan dengan cara soft copy maupun hard copy. Soft copy sangat dibutuhkan apabila diperlukan penggantian unit PLC atau akan membuat system kontrol yang baru dengan cara kerja yang sama dengan yang sudah ada, maka kemudahan yang didapatkan dari dokumentasi soft copy ini. Untuk pemrograman pada unit PLC yang baru, hanya perlu melakukan copy program dari dokumentasi soft copy.

\section{KESIMPULAN}

Dari hasil dan pembahasan Skripsi ini, dapat disimpulkan sebagai berikut:

1. Pemakaian Software G5000 untuk pemrograman ladder diagram lebih mudah diaplikasikan.

2. Pemakaian Software Scada untuk tampilan interface dengan Human Machine Interface.

3. Penggunaan software Scada dan diagram tangga serta instruksi diagram tangga yang umum digunakan dalam PLC beserta contoh pemakaiannya dalam program dapat dipahami dan diaplikasikan dengan mudah.

4. Penggunaan PLC XBC untuk fasilitas pengontrolan mempunyai banyak kelebihan dibandingkan dengan kontrol 
konvensional. Lebih mudah, lebih handal, lebih akurat, lebih mudah menganalisa apabila terjadi permasalahan

5. Perancangan Software engineering untuk sistem kontrol otomatisasi akan mempermudah dan lebih efisien dalam pengoperasian suatu peralatan.

6. Sebaiknya dalam pembuatan alat kontrol pilihlah bahan dan alat yang berkualitas baik, agar kontrol yang dihasilkan berkualitas baik. Terutama dalam pemilihan jenis PLC dan relayrelay yang diperlukan untuk antarmuka output.

\section{DAFTAR PUSTAKA}

Dedi Sumardi, 1989, Mengenal Teknik Digital, Andy Offset Yogyakarta.

Dian Artanto, 2009, "Membuat PLC Menggunakan Mikrokontroler”, AndyOffset Yogyakarta.
David Bailey, 2003, "Supervisory Control and Data Acquistion", Erlangga Jakarta.

Iwan Setiawan, "Programmable Logic Control (PLC) dan Teknik Perancangan Sistem Kontrol", Penerbit Andi Semarang, 2005.

Jogiyanto, H.M. 1995. Analisis dan Desain Sistem Informasi. Andy Offset Yogyakarta.

Malik, 2009, “ Teknik Dasar Logig Control, Andy Offset Yoyakarta.

Nebojsa Matic,2005, Introduction to PLC Controller, mikroelektronika.

Suhendar, 2005, "PLC Dalam Dasar-Dasar Sistem Kendali Motor Listrik Industri", Erlangga Jakarta

William Bolton, 2004, "Programmable Logic Control Edisi Ketiga”, Erlangga, Jakarta. 